Article

\title{
Floodplain Stability Indices for Sustainable Waterfront Development by Spatial Identification of Erosion and Deposition
}

\author{
Chang Geun Song ${ }^{1}$, Tae Geom Ku ${ }^{2}$, Young Do Kim ${ }^{3, *}$ and Yong Sung Park ${ }^{4}$ \\ 1 Department of Safety Engineering, Incheon National University, 119 Academy-ro, Yeonsu-gu, \\ Incheon 22012, Korea; baybreeze119@inu.ac.kr \\ 2 Department of Environmental Engineering, Inje University, 197 Inje-ro, Gimhae, Gyengnam 50834, Korea; \\ yhku1986@hotmail.com \\ 3 Department of Environmental Engineering, Nakdong River Environmental Research Center, \\ Inje University, 197 Inje-ro, Gimhae, Gyengnam 50834, Korea \\ 4 School of Science \& Engineering, University of Dundee, Perth Rd., Dundee DD1 4HN, UK; \\ y.s.park@dundee.ac.uk \\ * Correspondence: ydkim@inje.ac.kr
}

Academic Editors: Ebun Akinsete and Phoebe Koundouri

Received: 7 March 2017; Accepted: 25 April 2017; Published: 3 May 2017

\begin{abstract}
The abrupt rises of water level in rivers by torrential rain or storm repeatedly cause inundation damage, such as erosion and deposition in floodplains. However, studies on identifying the abrasion of waterfront facilities or the accumulation of sediment near rivers under extreme flow conditions are seldom found because floodplains are utilized in various ways in each country. In this study, novel floodplain sustainability indices by spatial classification of erosion and deposition were developed for sustainable waterfront development. The indices can provide the relative spatial distribution of erosion and deposition in a floodplain by using only kinematic flow information, such as flow depth and velocity obtained by 2D numerical analysis. Accordingly, applying a complex sediment transport model that involves numerous assumptions and parameters can be moderately replaced with the present approach. The suitability of developed indices was tested in several flow problems by comparing the predicted erosional or depositional region with measured data. In addition, the developed indices were applied to a floodplain in a natural river to examine the relative spatial distribution of the erosion and deposition for a typhoon event, and the results were compared with field monitoring data. It was found that deposition was more likely to occur than erosion in most floodplains, and the developed floodplain sustainability indices accurately quantified the erosion and deposition phenomena.
\end{abstract}

Keywords: erosion; deposition; floodplain stability indices; sustainable waterfront development

\section{Introduction}

Most rivers can be spatially classified into main channels, floodplains, or embankments. A wide range of waterfront facilities such as ecological parks and sports facilities have been established on the floodplains in Korea. However, the frequency and severity of flooding have increased because of climate changes, and the rise in the flood water level due to severe summer rainstorms has led to inundation damage such as the erosion and sedimentation of these waterfront facilities [1]. Accordingly, numerical analysis including floodplains should be carried out to estimate such flood damage, and two-dimensional (2D) numerical analysis is typically regarded as a viable option [2]. In this regard, stability evaluation indices for erosion and sedimentation can be calculated by using 2D numerical results, and flood damage in the floodplain can be assessed based on the indices. Studies on evaluating 
the flood hazard in a floodplain are seldom found because floodplains are unlikely to be a topic of research in countries other than the Republic of Korea, and only a small number of studies on the evaluation of flooding hazards have been undertaken. For example, Song et al. [3] indirectly evaluated the practical flood hazard presented by a typhoon with inland flood hazard indices. However, it is inappropriate to apply the inland flood hazard indices to Korean floodplains, because the flow structure varies significantly between inland urban areas and floodplains. Moreover, this index is based on statistics on the number of buildings that are inundated and the number of lives that are lost as a result of flooding, without consideration of erosion and sedimentation caused by flooding in a floodplain.

In this study, a transient erosion and deposition index (TEDI) and a steady erosion and deposition index (SEDI), which can work both for the erosion and sedimentation in a floodplain caused by flooding, were developed by using the Einstein-Krone formula. The applicability of the TEDI and SEDI was verified by applying a 2D finite element (FE) model [3-5] to the flow problems in previous studies to determine the erosion and sedimentation and compare the TEDI and SEDI obtained by numerical results. In addition, the developed indices were applied to the floodplains in a natural river to examine the relative spatial distribution of the erosion and sedimentation for a typhoon event.

\section{Model Description}

As Song et al. [3] showed, flow depth and velocity are significant parameters that influence flood damage and subsequently sediment transport. Accordingly, the present mathematical model to predict the spatial distribution of erosion and deposition, respectively, is the 2D Saint-Venant equation:

$$
\begin{gathered}
\frac{\partial h}{\partial t}+h \nabla \times \underline{u}+\underline{u} \times(\nabla h)=0 \\
\frac{\partial \underline{u}}{\partial t}+(\underline{u} \times \nabla) \underline{u}=-g \nabla(H+h)+\frac{1}{h} \nabla \times(h v \nabla \underline{u})-\frac{g n^{2}}{h^{4 / 3}} \underline{u}\|\underline{u}\|
\end{gathered}
$$

where $t=$ time; $\underline{u}=\left(u_{1}, u_{2}\right)$ is the vertically-averaged velocity vector in the $x$-and $y$-directions, respectively; $g=$ acceleration due to gravity; $H=$ bottom elevation; $h=$ flow depth; $v=$ kinematic eddy viscosity; $n=$ roughness coefficient; and $\|\underline{u}\|=$ velocity magnitude [5].

The Petrov-Galerkin stabilizing scheme was employed to discretize the governing equations because it yields a stable and accurate prediction under severe flood flow without any parameter adjustment [6]. During and after a flood event, the condition of the floodplain can change between wetting and drying. This phenomenon is closely related with the erosion and deposition of the floodplain. Therefore, a flow model should be capable of handling the element transition between submergence under water and exposure to the atmosphere. In this study, following the approach of Song et al. [3], a Eulerian method with a flux-blocking scheme was adopted to incorporate dry nodes in the floodplain. The velocity corresponding to the dry node is set to be zero. If the depth increases more than the dry depth in the next iteration, the node is activated as a wet condition.

In this study, the result acquired by applying the numerical model has a very significant meaning because it determines the spatial identification of erosion and deposition. Accordingly, the model performance or capability should be checked, and previous studies on the verification of the applied model can be found as follows: In Seo et al. [7], the accuracy of the model results was demonstrated by comparing the numerical solutions with analytic solutions, available numerical results, and experimental data; Song and Oh [6] tested the model in transient flow problems under temporal or spatial variation; in addition, specific features of the flow model were described by Park et al. [8]. 


\section{Development of Erosion and Deposition Indices}

In this study, TEDI (Transient Erosion and Deposition Index) was proposed to evaluate the relative spatial distribution of erosion and sedimentation in floodplains by using the Einstein-Krone formula:

$$
D=\omega P_{d} C_{a}=\omega\left(1-\frac{\tau_{b}}{\tau_{c d}}\right) C_{a}
$$

where, $D=$ deposition flux $\left(\mathrm{kg} / \mathrm{m}^{2} / \mathrm{s}\right) ; \omega=$ settling velocity of a single particle in tranquil water $(\mathrm{m} / \mathrm{s}) ; P_{d}=$ probability of settled particles remaining deposited; $C_{a}=$ near-bed volumetric sediment concentration $\left(\mathrm{kg} / \mathrm{m}^{3}\right) ; \tau_{b}=$ local bed shear $\left(\mathrm{N} / \mathrm{m}^{2}\right)$; and $\tau_{c d}=$ critical shear stress for deposition $\left(\mathrm{N} / \mathrm{m}^{2}\right)$.

In Equation (3), because $\tau_{c d}, \omega$, and $C_{a}$ are typically prescribed as specific values, only local bed shear caused by bottom friction can be changed according to the results of the modeling. For this reason, terms other than $\tau_{b}$ can be regarded as being constants. In the Einstein-Krone formula, sedimentation occurs when $\tau_{b}$ is smaller than $\tau_{c d}$, while erosion occurs when $\tau_{b}$ is greater than $\tau_{c d}$. $\tau_{b}$ can be calculated through the application of following friction stress formula [9]:

$$
\tau_{b}=\frac{1}{2} \rho_{s} f_{c} V^{2}
$$

where, $\rho_{s}=$ sediment particle density $\left(\mathrm{kg} / \mathrm{m}^{3}\right) ; f_{c}=$ friction factor; and $V=$ cross-sectional average velocity $(\mathrm{m} / \mathrm{s})$. Because $\rho_{s}$ can be assumed to be a constant, and $f_{c}$ and $V$ are functions of time, differentiating $\tau_{b}$ with respect to time yields Equation (5):

$$
\frac{d \tau_{b}}{d t}=\frac{1}{2} \rho_{s} \frac{d f_{c}}{d t} V^{2}+\rho_{s} f_{c} V \frac{d V}{d t}
$$

In Equation (5), the time rate of change of $f_{c}$ is very small during a short flood event because $f_{c}$ is mainly determined by the channel shape, size, slope, and surface conditions [10]. Thus, Equation (5) is reduced to:

$$
\frac{d \tau_{b}}{d t} \approx \rho_{s} f_{c} V \frac{d V}{d t}=\rho_{s} f_{c} V a
$$

where $a=d V / d t$ is the local acceleration. Combining Equations (3) and (6) results in Equation (7):

$$
\frac{d D}{d t}=\omega C_{a}\left(-\frac{1}{\tau_{c d}}\right) \frac{d \tau_{b}}{d t}=-\frac{\omega C_{a}}{\tau_{c d}} \rho_{s} f_{c} V a=- \text { constant } \times V a
$$

According to the above equation, the time rate of change of the deposition flux is negatively proportional to the product of the flow velocity and acceleration, and the deposition flux rate has a maximum value at a point at which $V a$ is the lowest. Consequently, in this study, $V a$ is defined as the TEDI.

Another index, SEDI (Steady Erosion and Deposition Index) was proposed to estimate the relative sedimentation rate by averaging the bottom shear stress during a certain flood wave in a section. $\tau_{b}$, which determines the movement of the sediment particles during steady-uniform flow, is given by Equation (8):

$$
\tau_{b}=\gamma h S
$$

where $\gamma$ is the specific weight of water $\left(\mathrm{N} / \mathrm{m}^{3}\right) ; h$ is the flow depth $(\mathrm{m})$; and $S$ is the channel slope. Substituting $S$ by introducing the Manning formula $V=\frac{1}{n} h^{2 / 3} S^{1 / 2}$ gives:

$$
\tau_{b}=\gamma n^{2} V^{2} h^{-1 / 3}
$$


Therefore, $\tau_{b}$ is a function of $V^{2}$ and $h^{-1 / 3} . \tau_{c d}$ can be calculated by using the Shields relation in Equation (10):

$$
\tau_{*_{c}}=\frac{\tau_{c d}}{\left(\gamma_{s}-\gamma\right) d_{s}}
$$

Finally, taking the ratio of $\tau_{b}$ in Equation (9) and $\tau_{c d}$ in Equation (10), we arrive at:

$$
\frac{\tau_{b}}{\tau_{c d}}=\frac{\gamma n^{2} V^{2} h^{-1 / 3}}{\tau_{*_{c}}\left(\gamma_{s}-\gamma\right) d_{s}}=\frac{\gamma n^{2}}{\tau_{*_{c}}\left(\gamma_{s}-\gamma\right) d_{s}} \frac{V^{2}}{h^{1 / 3}}=\text { constant } \times \frac{V^{2}}{h^{1 / 3}}
$$

In the above equation, the properties related to sediment particles can be regarded as constants, and $\frac{V^{2}}{h^{1 / 3}}$ is defined as the SEDI.

Although the TEDI and SEDI proposed in this study cannot quantitatively provide the amount of erosion and deposition, they can represent the relative spatial distribution of erosion and sedimentation in a target area in the case of flooding by using only fluid kinematic information, such as flow velocity, acceleration, and depth of water, without the application of a complex sediment transport model.

\section{Verifications of Proposed Indices}

In this section, two sets of experimental data available in literature [11,12] were considered. Peakall et al. [12] conducted experiments in a flume with a meandering channel, while Guillén-Ludeña et al. [11] used a confluent channel. To verify the proposed indices, numerical simulations were implemented under the same conditions as in the two sets of experimental data. Post-processing of the numerical results were carried out using Tecplot 360, yielding the required parameters such as flow velocity and flow depth for computing TEDI and SEDI values.

\subsection{Meandering Channel}

A numerical simulation was carried out under the same conditions as those applied to a hydraulic experimental channel in Peakall et al. [12], and the spatial distribution of the TEDI and SEDI was compared with measured data to analyze the applicability of the developed indices. The channel was $0.15 \mathrm{~m}$ wide, $1.52 \mathrm{~m}$ long, and had slope of $3^{\circ}$. Initially the channel was evenly filled with sediment of diameter $0.025 \mathrm{~m}$ and the bottom changes were measured after water flowed over a given period of time. Finite elements were generated using the channel geometry by Peakall et al. [12], as shown in Figure 1, and an unsteady simulation was conducted under the boundary conditions described in Table 1.

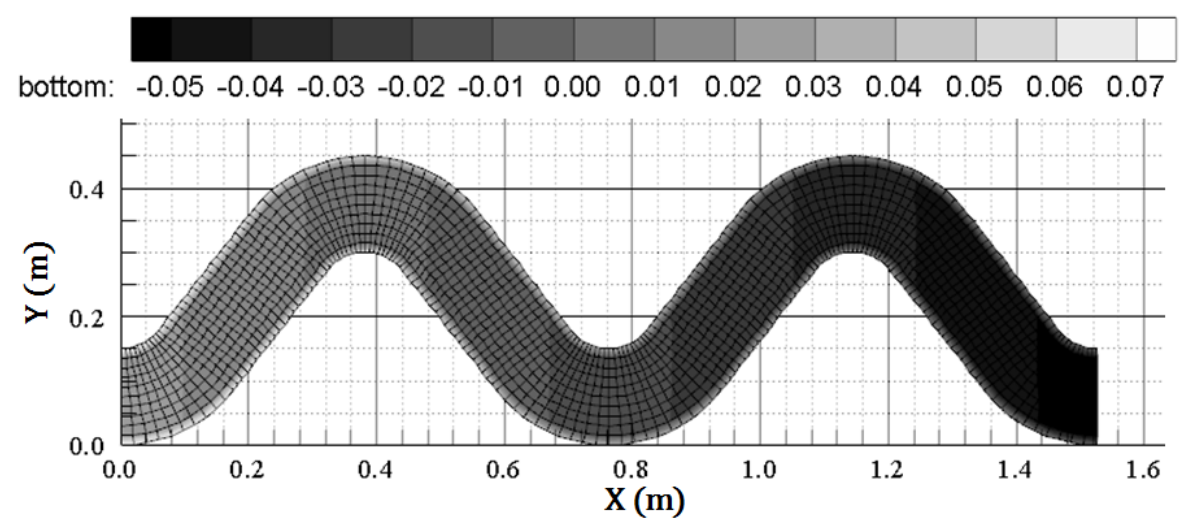

Figure 1. Topography and finite elements for the meandering channel.

The TEDI and SEDI were calculated based on the results of applying the 2D FE model, which was introduced in Section 2. Since the minimum, maximum and the range of these two indices are different, they should be normalized to have a value between 0 and 1.0 in order to compare them with 
each other. To determine the normalization factor, the values of percentiles, maximum, minimum, and mean were considered (see Table 2). Figure 2 shows the corresponding box and whisker plot. After several repeated tests, it has been concluded that the normalization factor by the mean value showed good agreement with the experimental observations. Therefore, the TEDI and SEDI at every node were normalized by the average values for generalization and visualization purposes.

Table 1. Boundary conditions for the meandering channel [12].

\begin{tabular}{cc}
\hline Discharge & Downstream Elevation \\
\hline $1.25 \times 10^{-3} \mathrm{~m}^{3} / \mathrm{s}$ & $0.1 \mathrm{~m}$ \\
\hline
\end{tabular}

Table 2. Percentile and statistical values for Transient Erosion and Deposition Index (TEDI) and Steady Erosion and Deposition Index (SEDI) representation.

\begin{tabular}{cccccccc}
\hline Index & $\mathbf{5 p}$ & $\mathbf{2 5 p}$ & $\mathbf{7 5 p}$ & $\mathbf{9 5 p}$ & Mean. & Min. & Max. \\
\hline TEDI $\left(\mathrm{m}^{2} / \mathrm{s}^{3}\right)$ & -0.15 & 0.01 & 0.34 & 0.73 & 0.20 & -0.30 & 1.20 \\
SEDI $\left(\mathrm{m}^{5 / 3} / \mathrm{s}^{2}\right)$ & 0.07 & 0.11 & 0.29 & 0.58 & 0.24 & 0.05 & 1.55 \\
\hline
\end{tabular}

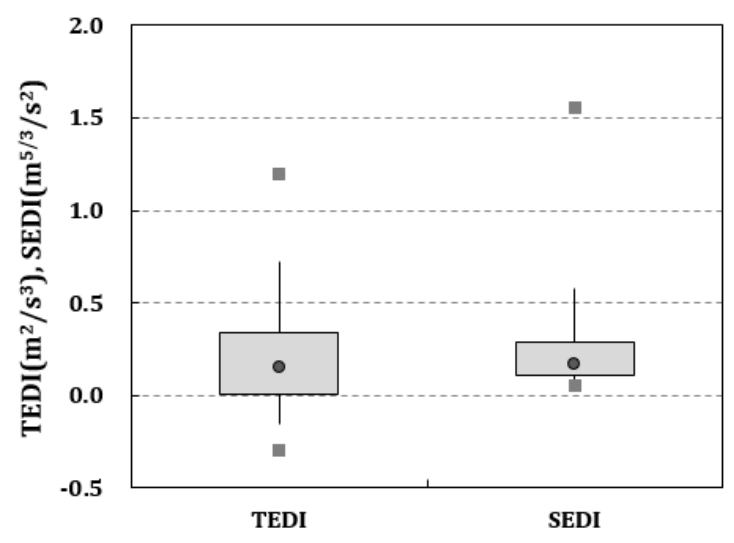

Figure 2. Box and whisker plot for TEDI and SEDI.

Figure 3 shows the normalized TEDI and SEDI. As the value approaches 1.0, erosion is likely to occur at that location. In contrast, as it approaches 0 , the possibility of deposition becomes higher. It is well known that erosion occurs at the inner bank, and deposition is observed at the outer bank in an experimental meandering channel with a rectangular cross-section [13]. Figure 3 indicates that there were sections where erosion or deposition are likely to occur. These results were similar to the experimental results by Peakall et al. [12]. The TEDI had a wider range of values than the SEDI because the TEDI was more sensitive to temporal changes of velocities at the inner and outer sections by unsteady simulations.

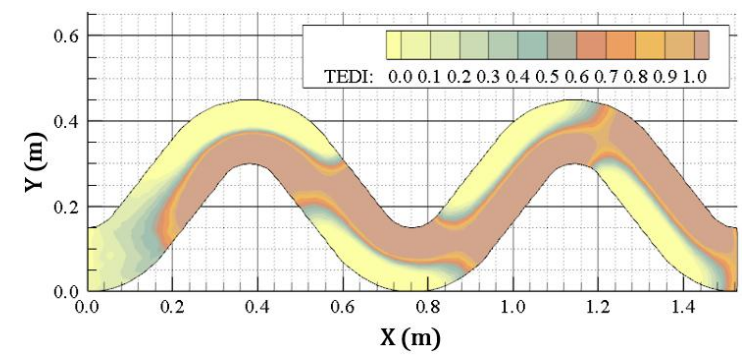

(a) TEDI

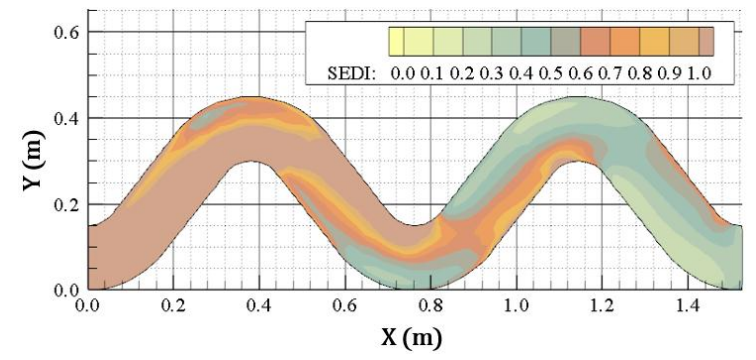

(b) SEDI

Figure 3. Result of calculating indices for the meandering channel. (a) TEDI; (b) SEDI. 


\subsection{Confluent Channel}

In this section, another numerical simulation was carried out under the same conditions as those applied to the experimental channel by Guillén-Ludeña et al. [11]. The main channel was $0.5 \mathrm{~m}$ wide and $3.5 \mathrm{~m}$ long, and the tributary was $0.15 \mathrm{~m}$ wide and $3 \mathrm{~m}$ long, flowing downward. The bottom elevation is shown in Figure 4, which is identical to the experimental setup used in Guillén-Ludeña et al. [11]. The simulation was conducted for $14 \mathrm{~h}$, and the boundary conditions are described in Table 3.

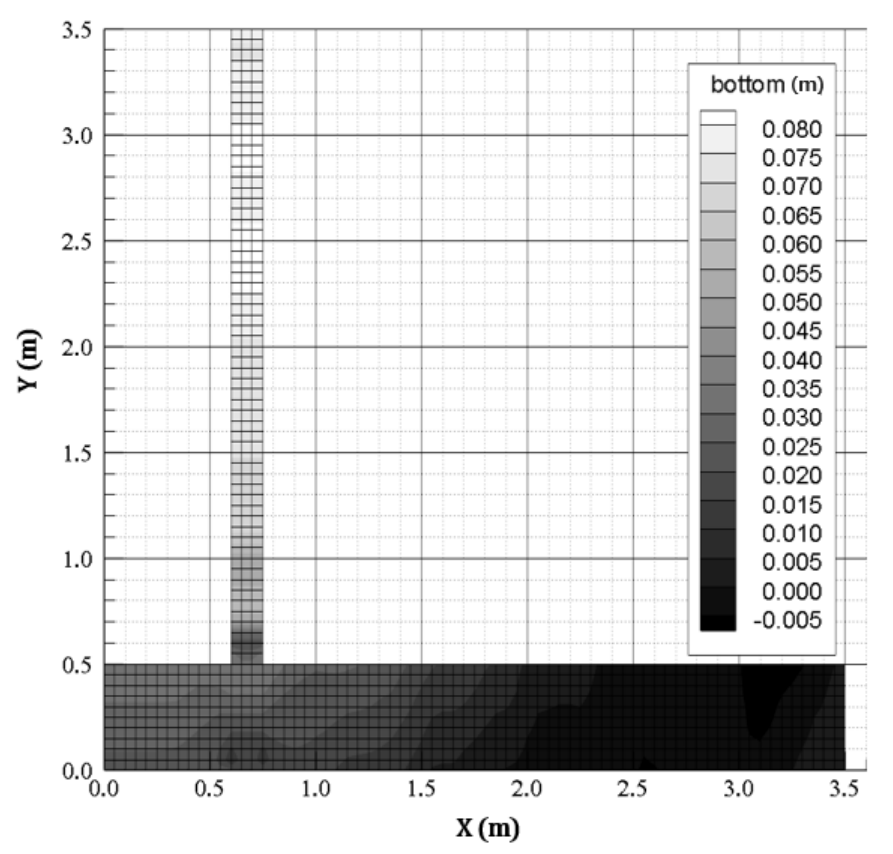

Figure 4. Topography and finite elements for the confluent channel.

Table 3. Boundary conditions for the confluent channel [11].

\begin{tabular}{ccc}
\hline Main Channel & Tributary & Downstream Elevation \\
\hline $27.0 \mathrm{~L} / \mathrm{s}$ & $3.0 \mathrm{~L} / \mathrm{s}$ & $0.12 \mathrm{~m}$ \\
\hline
\end{tabular}

Figures 5 and 6 show the normalized TEDI and SEDI, respectively, and in terms of erosion and sedimentation in the main stream, it was estimated that erosion occurred close to the outer bank at a region approximately $45^{\circ}$ after the confluence of the main stream and tributary while deposition occurred close to the inner bank. Although the results shown in Figures 5 and 6 differ slightly, both the TEDI and SEDI predict that the location of maximum erosion should form between $1.0 \mathrm{~m} \leq x \leq 2.5 \mathrm{~m}$. Guillén-Ludeña et al. [11] reported similar observations in their experiments, thereby supporting that the TEDI and SEDI are useful indicators for the prediction of erosion and sedimentation. 


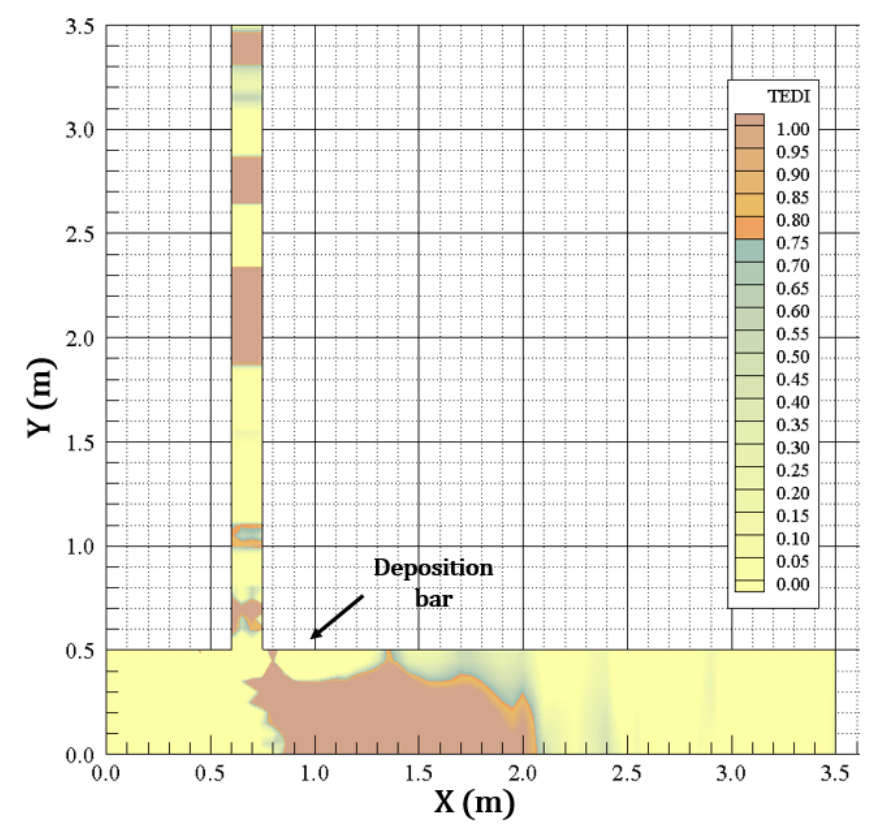

Figure 5. Results of calculating the TEDI for the channel of $90^{\circ}$.

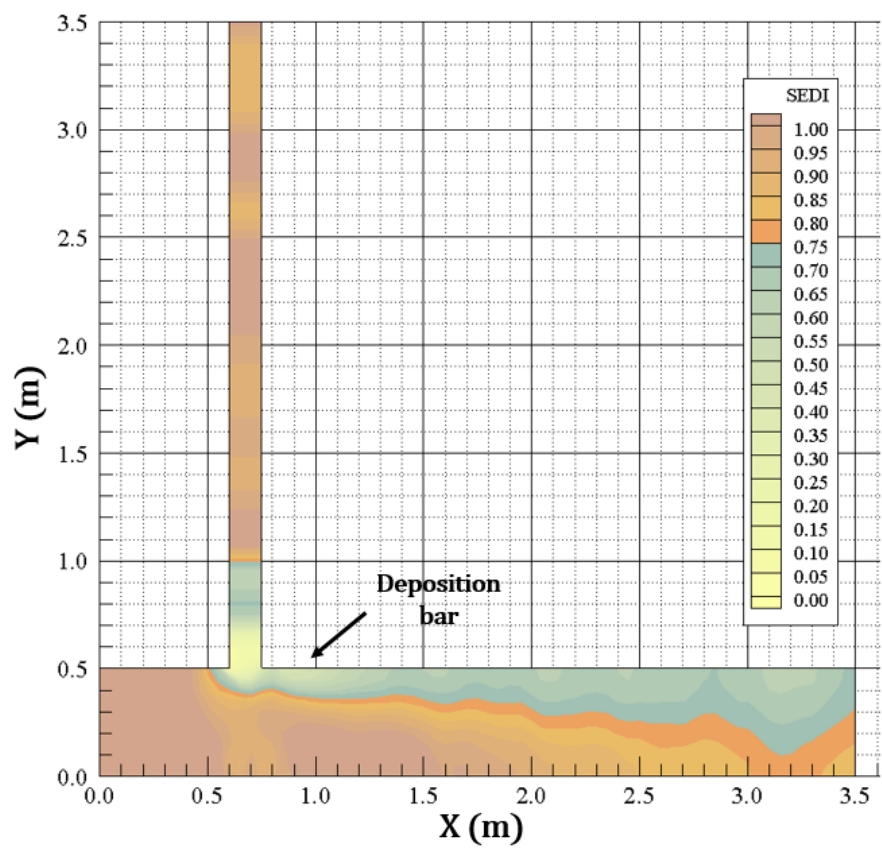

Figure 6. Results of calculating the SEDI for the channel of $90^{\circ}$.

\section{Application to Floodplains in a Natural River}

\subsection{Description of Simulation Conditions}

To apply the TEDI and SEDI proposed in this study to a field problem, a target region was selected as shown in Figure 7. The length of the section was approximately $15 \mathrm{~km}$ and stretched from the Hwawon water level observation station located in Dalseong-gun, Daegu-si, Republic of Korea to a direct upstream area of the Dalseong reservoir. Various waterfront facilities such as sports parks and artificial wetlands have been established in the floodplains within the simulation area; the four sites indicated in Figure 7 were monitored after the occurrence of Typhoon Sanba. 


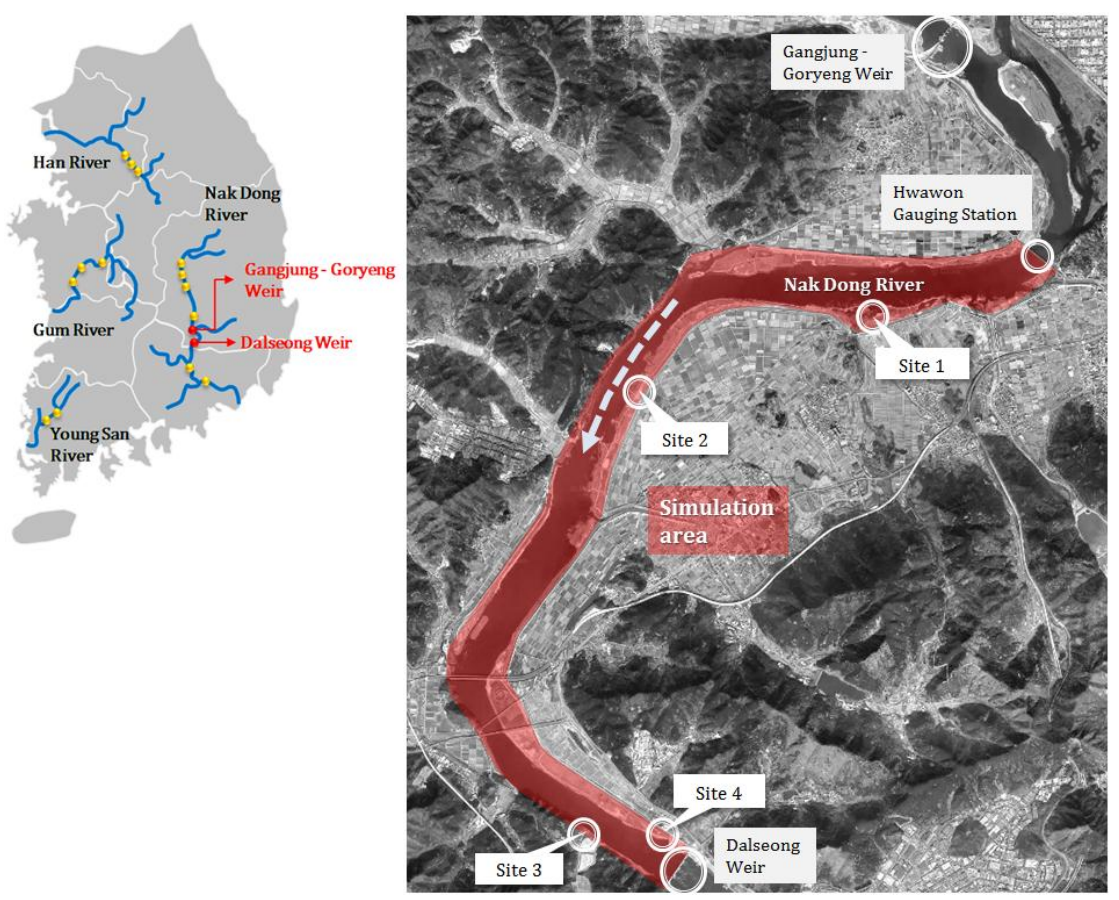

Figure 7. Simulation area and monitoring sites.

The upstream boundary condition was assigned by the discharge measured at the Hwawon station between 11 a.m. on 17 September 2012 and 5 a.m. on 19 September 2012 under the influence of Typhoon Sanba. For downstream boundary conditions, the water level computed by the Hydrologic Engineering Center's River Analysis System (HEC-RAS) model [1] was employed (see Figure 8). Moreover, to verify the 2D FE model, a quasi-unsteady simulation was carried out for $42 \mathrm{~h}$, including the peak flood passage of Typhoon Sanba. The detailed verification can be found in Song et al. [3].

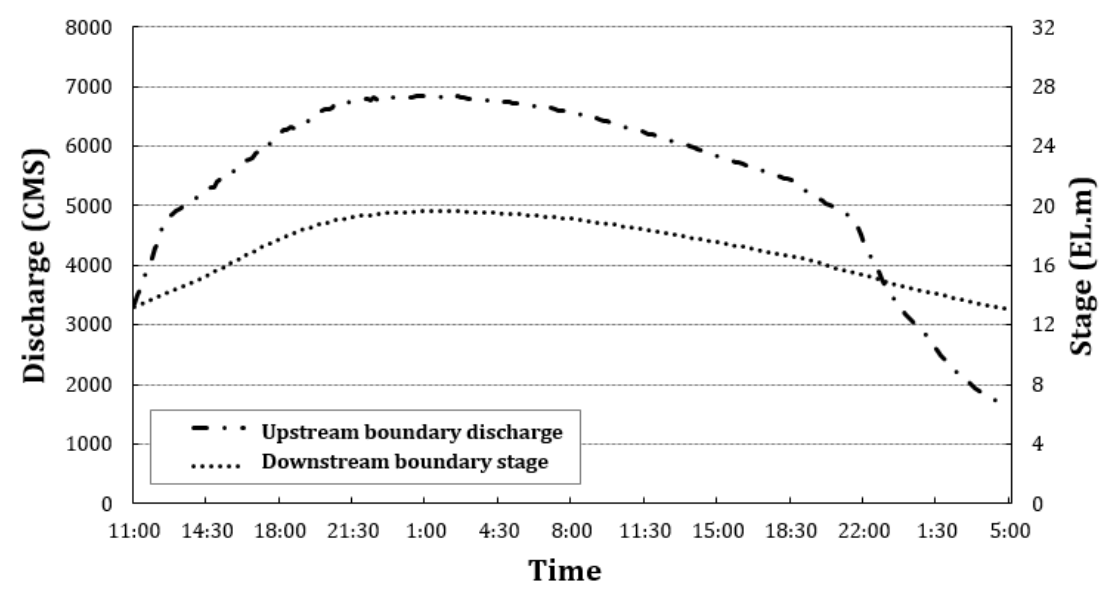

Figure 8. Boundary conditions for the natural river application.

\subsection{Prediction of Erosion and Deposition}

Song et al. [3] showed that the water is contained inside the main channel of a river at the beginning of the flooding. However, when the flood peak arrived, most of the floodplain was submerged, and after the flood event, erosion and deposition could be observed in the floodplain. Normalized TEDI and SEDI were calculated at the flood peak moment, and are provided in Figures 9 and 10. The areas marked in white in these figures refer to those areas of the floodplains that are not flooded. In Figures 9 
and 10, the discrepancy between the predictions of TEDI and SEDI just before Site 3 can be explained as follows: Just before and after the flood peak, which corresponds to the time near 1:00 in Figure 8, the discharge and water stage remain almost constant. In this study, a quasi-unsteady simulation was implemented with a short timestep. This means that flow characteristics, especially acceleration, do not change significantly according to the time. Consequently, TEDI, represented by product of velocity and acceleration, has a small value due to the weak acceleration at the lower part of simulation domain. In contrast, SEDI provides an averaged estimation of the sedimentation rate by computing $\frac{V^{2}}{h^{1 / 3}}$ over a timestep. Therefore, TEDI is relatively small compared with SEDI in the simulation area, except in the upstream areas before and after the first bend in the quasi-unsteady simulation. On the other hand, for the SEDI, the relative aspect between the deposition and erosion at the inner and outer sections of the second bend exhibited a considerable difference because the deposition and erosion were classified according to the flow velocity and depth of the water. In addition, deposition was more likely to occur than erosion in most floodplains.

To confirm the prediction of the TEDI and SEDI, field monitoring was performed after Typhoon Sanba, and the status of waterfront facilities within the floodplains was checked at monitoring sites for comparison (Figure 7). A park, including a soccer field and a basketball court was located at Site 1, while an ecological park and a rest area were located at Site 2. Site 3 was selected as a monitoring site because revetment erosion occurred even though there was no specific waterfront facility; at Site 4, a fishway was located directly upstream at the Dalseong reservoir.

Figure 11 presents images of the four monitoring sites in Figure 7 after Typhoon Sanba. The waterfront facilities could not be utilized due to sand sedimentation over the sites, with the exception of Site 3, where significant erosion of a low-flow revetment occurred. By comparing the monitoring results with Figures 9 and 10, the values of the calculated indices were lower at Sites 1, 2, and 4 where sedimentation occurred, and these values were higher at Site 3 where erosion occurred. Thus, the results of comparing the indices with the images of practical site monitoring after a typhoon event confirmed that TEDI and SEDI accurately identified the erosion and deposition phenomena. Although TEDI and SEDI cannot quantitatively calculate the amount of erosion and deposition, they can provide the relative spatial distribution of erosion and sedimentation in a floodplain by using only kinematic flow information such as flow depth and velocity without applying a complex sediment transport model that involves numerous assumptions and parameters.

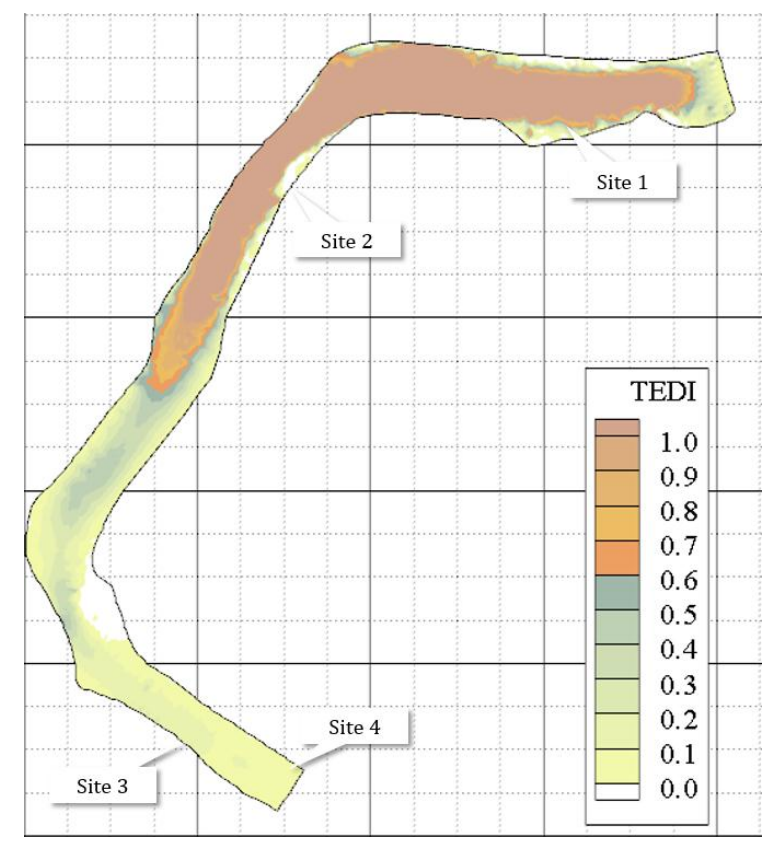

Figure 9. The TEDI at flood peaks. 


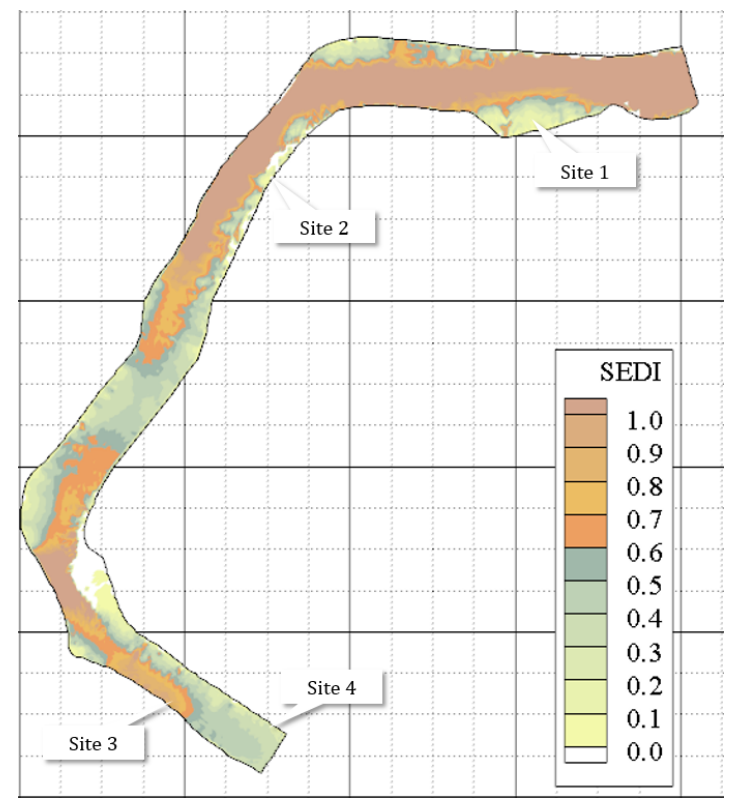

Figure 10. The SEDI at flood peaks.

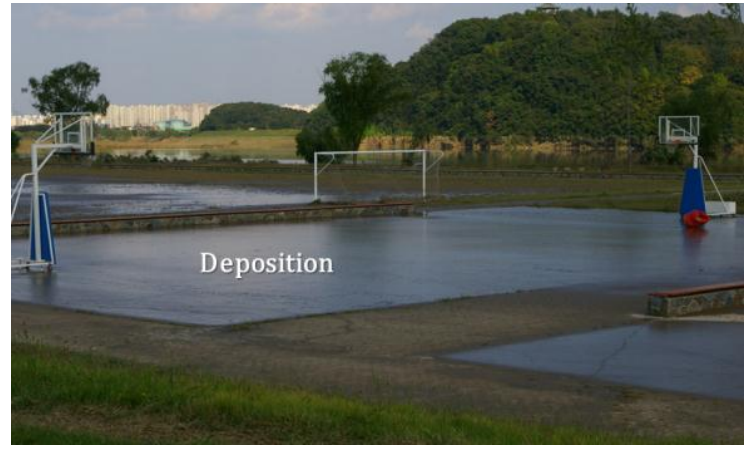

(a) Site 1

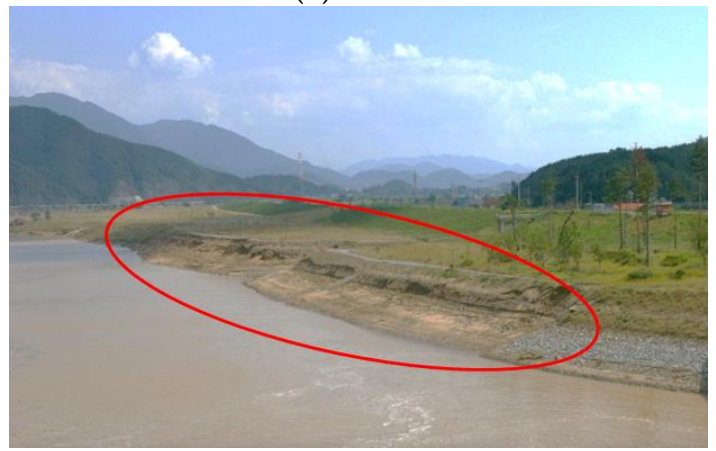

(c) Site 3

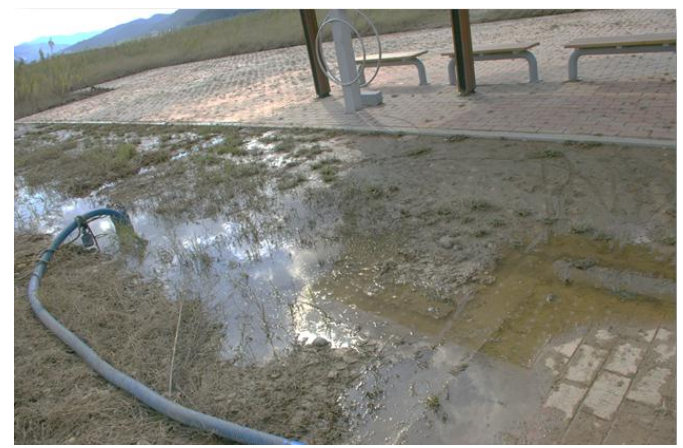

(b) Site 2

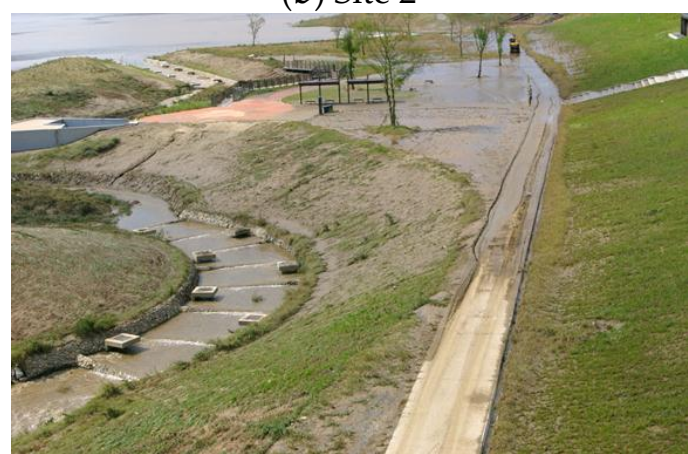

(d) Site 4

Figure 11. Images of monitoring sites. (a) Site 1; (b) Site 2; (c) Site 3; (d) Site 4.

\section{Conclusions}

Various waterfront facilities have been built on the floodplains after the Four Major Rivers Project in the Republic of Korea. However, sediment deposited after storms or torrential rains repeatedly led to significant restoration costs. In this study, two indices were developed to predict the spatial distribution of erosion and deposition in floodplains during or after severe rainstorms. The summary and findings of this study are described as follows. 
(1) In general, we should run a sediment transport model to predict the spatial distribution of erosion or deposition. However, to run a sediment transport model, a large number of empirical parameters, such as settling velocity, diffusion coefficient, density of bed material, critical shear stress, erosion rate and so on, are necessary. Therefore, determining these values is a very onerous procedure. Furthermore, because the flow information, such as velocity and water depth, are essential parameters to run a sediment transport model, a hydrodynamic flow modeling should be preceded before applying the sediment transport model. Accordingly, paying attention to this aspect, novel floodplain sustainability indices were developed to estimate the relative spatial distribution of erosion and sedimentation in a target area in the case of flooding. The indices only require kinematic flow information such as flow depth and velocity obtained by 2D flow modeling.

(2) The applicability of the TEDI and SEDI was verified by applying a 2D finite element (FE) model to two flow problems. In the meandering channel application, the sections predicted by two indices were similar to the experimental results, and the TEDI had a wider range of values than the SEDI because the TEDI was more sensitive to temporal changes of velocities at inner and outer sections by unsteady simulations. In the confluent channel problem, the location of maximum erosion was in good agreement with the experimental observations. Consequently, the TEDI and SEDI produced a valid result for the prediction of erosion and sedimentation.

(3) The TEDI and SEDI were calculated at the flood peak of Typhoon Sanba. Overall, the TEDI was smaller than the SEDI because the acceleration was insignificant in the simulation area. In addition, deposition was more likely to occur than erosion in most floodplains. Comparing the index values with the images of field site monitoring after a typhoon event confirmed that the TEDI and SEDI accurately identified the erosion and deposition phenomena.

Further studies are designed to present individual indices for classifying the prevalence of sedimentation, and to categorize the erosional or depositional damage level during or after flooding or severe rainstorms.

Acknowledgments: This research was made possible by the support of the Water Management Research Project (11-Technology Innovation-C06) of the Ministry of Land, Infrastructure, and Transport. We would like to express our gratitude for the support we have received and the geographical data on bed elevation changes, which were obtained by Siwan Lyu's laboratory, Changwon National University, Korea.

Author Contributions: Chang Geun Song and Tae Geom Ku modified the two-dimensional numerical model and performed hydrodynamic simulations. Young Do Kim and Yong Sung Park analyzed floodplain stability with the results of hydrodynamic simulations. Also, all authors conceived and wrote together this paper.

Conflicts of Interest: The authors declare no conflict of interest.

\section{References}

1. Ku, Y.H.; Song, C.G.; Kim, Y.D.; Seo, I.W. Analysis of Hydraulic Characteristics of Flood Plain Using Two-Dimensional Unsteady Model. J. Korean Soc. Civ. Eng. KSCE 2013, 33, 997-1005. (In Korean). [CrossRef]

2. Sato, S.; Imamura, F.; Shuto, N. Numerical simulation of flooding and damage to houses by the Yoshida River due to Typhoon No. 8610. J. Nat. Disaster Sci. 1989, 11, 1-19.

3. Song, C.G.; Ku, Y.H.; Kim, Y.D.; Park, Y.S. Stability analysis of riverfront facility on inundated floodplain based on flow characteristics. J. Flood Risk Manag. 2016, 9. [CrossRef]

4. Seo, I.W.; Song, C.G. Element Model for the Analysis of Shallow Water Flow. J. Korean Soc. Civ. Eng. KSCE 2010, 30, 199-209. (In Korean).

5. Seo, I.W.; Song, C.G. Numerical simulation of laminar flow past a circular cylinder with slip conditions. Int. J. Numer. Methods Fluids 2012, 68, 1538-1560. [CrossRef]

6. Song, C.G.; Oh, T.K. Transient SU/PG modeling of discontinuous wave propagation. Prog. Comput. Fluid Dyn. Int. J. 2016, 16, 146-162. [CrossRef]

7. Seo, I.W.; Kim, Y.D.; Song, C.G. Validation of depth-averaged flow model using flat-bottomed benchmark problems. Sci. World J. 2014, 2014, 197539. [CrossRef] [PubMed] 
8. Park, I.H.; Seo, I.W.; Kim, Y.D.; Song, C.G. Flow and dispersion analysis of shallow water problems with Froude number variation. Environ. Earth Sci. 2016, 75, 120. [CrossRef]

9. Fanning, J.T. A Practical Treatise on Hydraulic and Water-Supply Engineering; D. Van Nostrand: New York, NY, USA, 1892.

10. Henderson, F.M. Open Channel Flow; Macmillan: London, UK, 1996.

11. Guillén-Ludeña, S.; Franca, M.J.; Cardoso, A.H.; Schleiss, A.J. Hydro-morphodynamic evolution in a $90^{\circ}$ movable bed discordant confluence with low discharge ratio. Earth Surf. Process. Landf. 2015. [CrossRef]

12. Peakall, J.; Amos, K.J.; Keevil, G.M.; Bradbury, W.; Gupta, S. Flow processes and sedimentation in submarine channel bends. Mar. Pet. Geol. 2007, 24, 470-486. [CrossRef]

13. Dietrich, W.E.; Whiting, P. Boundary shear stress and sediment transport in river meanders of sand and gravel. In River Meandering; American Geophysical Union: Washington, DC, USA, 1989; pp. 1-50.

(C) 2017 by the authors. Licensee MDPI, Basel, Switzerland. This article is an open access article distributed under the terms and conditions of the Creative Commons Attribution (CC BY) license (http:/ / creativecommons.org/licenses/by/4.0/). 